\title{
THE SELF AS A COLLECTION OF MULTIPLE SELF-ASPECTS: STRUCTURE, DEVELOPMENT, OPERATION, AND IMPLICATIONS
}

\author{
Allen R. McConnell, Tonya M. Shoda, and Hayley M. Skulborstad \\ Miami University
}

\begin{abstract}
What is the self? This age-old question is one that, surprisingly, receives little attention even among researchers who study it. In our view, addressing this important question begins with acknowledging that the self is composed of multiple, context-dependent self-aspects represented in an interrelated memory network. These self-aspects develop in the service of pursuing important self-relevant goals (e.g., reproduction, achievement, belongingness) and reflect one's important qualities exhibited in these domains. Because context activates a goal-relevant self-aspect, discrete subregions of self-knowledge are activated at any given time, which limits the impact of core personality attributes and shapes the experience of current affect. This approach has broader implications for explaining how the self can be both stable yet variable, for the conditions under which self-concepts develop and change, for distinguishing between the self as the known and the knower, and for goal pursuit and self-regulatory activities.
\end{abstract}

Addressing the question of "what is the self?" is an age-old pursuit of scholars, ranging from philosophers to clergy to poets. More recently, psychologists have engaged this issue by considering the self as both an entity that we understand and as an emergent phenomenon that shapes our perceptions (James, 1890). In the past 50 years, the field has witnessed an explosion of research on the self, exploring topics such as self-concept, self-esteem, self-complexity, self-regulation, and self-schemas just to name a few. But what is this self that these important lines of research seek to understand? Although we would not be as bold as to suggest definitive answers to this timeless question, we believe that the social cognition

\footnotetext{
This work supported by the Lewis Endowed Professorship.

Correspondence concerning this article should be addressed to Allen R. McConnell, Department of Psychology, Miami University, Oxford, OH 45056; E-mail: mcconnar@muohio.edu.
} 
perspective provides meaningful insights that bring us closer to a more comprehensive understanding of the self.

\section{BASIC PROPERTIES OF THE SELF}

To begin addressing this question, we must first identify the basic properties to which the self must adhere. First, the self is memory. People may speak of things such as one's heart, one's soul, one's motivation, and one's appearance, but ultimately, the self that interests psychologists is contained inside one's brain. For example, although we may recognize an elderly relative based on her current physical appearance and behaviors from across a crowded room, observing that she suffers seriously from Alzheimer's disease will reveal that her knowledge of who she is currently has been disrupted by a medical condition that ravages her memory and leaves her connected to past experiences and identities instead of recent events and her current personality (e.g., Klein, Cosmides, \& Costabile, 2003). Second, this self-knowledge is represented in memory in an organized fashion. Indeed, much of the important pioneering work on the social cognition of the self established that the self is a rich, elaborative memorial structure (e.g., Bower \& Gilligan, 1979; Greenwald \& Banaji, 1989; Klein \& Kihlstrom, 1986; Markus, 1977). Finally, we would contend that the self is not a unitary concept, but rather is a collection of multiple self-relevant identities. Although the notion of a single, true self may reflect a cultural caricature for those endorsing a relatively strong independent self-construal (e.g., Markus \& Kitayama, 1991; Spencer-Rodgers, Williams, \& Peng, 2010; Triandis, 1989), a great deal of recent work in social cognition has supported the position that the self-concept is composed of many self identities (e.g., Kurzban \& Aktipis, 2007; Linville \& Carlston, 1994; McConnell, 2011). Indeed, much of the work in our lab has focused on how one's self-aspects (i.e., one's context-dependent self identities such as wife, athlete, or professor) exist in an interrelated associative network in memory, influencing one's health, emotions, goal pursuit, and mental regulation (e.g., Brown \& McConnell, 2009, 2011; McConnell et al., 2005; McConnell, Rydell, \& Brown, 2009; Renaud \& McConnell, 2002; Schleicher \& McConnell, 2005).

Before going further, we should be clear about the scope of "the self" that we explore in the current analysis. For example, James (1890) identified different constituents of the self, including the material self (e.g., one's body), the spiritual self (e.g., one's faculties), and the social self (e.g., one's social facets). Herein, we accent the social self because of its relevance to social psychology. Also, although there have been many functionally distinct systems identified for the self such as diachronicity (continuity through time) and agency and ownership (see Klein \& Gangi, 2010), we focus on the memorial aspects of the self, including episodic and semantic self-knowledge, because of their interest to social cognition researchers.

\section{THE DEVELOPMENT OF SELF-ASPECTS}

Identifying the basic properties of the self is useful in that it begins to sketch an outline of what ultimately becomes the self in memory. We provide an example of Danielle in Figure 1 to illustrate several principles. As noted previously, we 


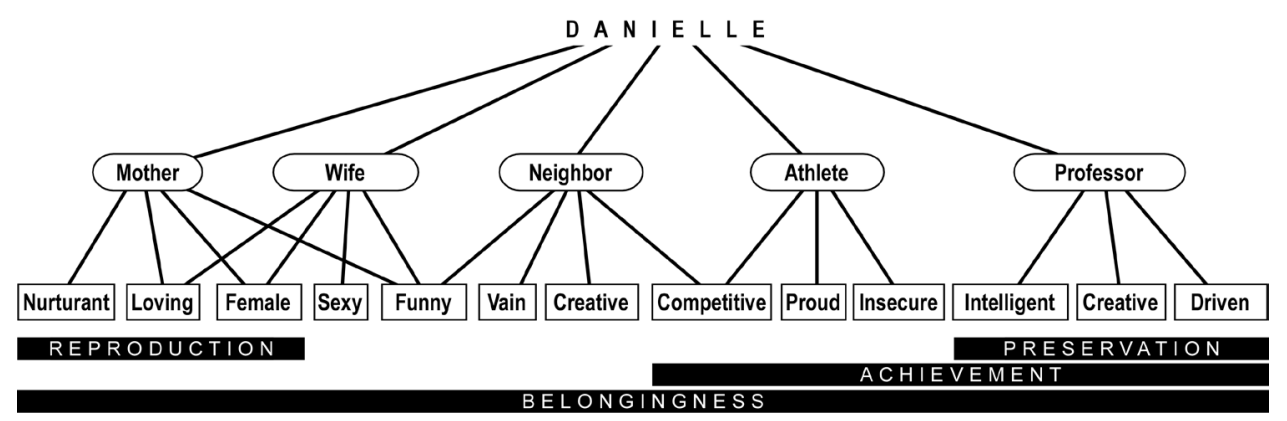

FIGURE 1. Self-concept representation for Danielle, including her multiple self-aspects (ovals), associated attributes (rectangles), and the underlying motives served by each self-aspect (reverse text).

view the self-concept as a collection of multiple self-aspects (the ovals, indicating context-dependent identities such as mother and professor) that are uniquely associated with the self in memory. Yet, it is important to identify how these contextdependent selves come into being. By explicating the manner in which these selfaspects are instantiated, a fuller account of what is the self emerges. For instance, even though several literatures discuss meaningful consequences of having multiple self-aspects, including research on self-compartmentalization (see Showers \& Zeigler-Hill, 2003) and on self-complexity (see McConnell \& Strain, 2007), there is little discussion about how these context-dependent multiple selves are produced in the first place. In our view, each self-aspect is a distinct psychological canvas that exhibits one's significant needs, goals, and motives (presented at the bottom of Figure 1). For example, Danielle's mother self-aspect emanates from her reproductive goals, which are an outgrowth of basic evolutionary pressures. On the other hand, her neighbor self-aspect is the product of her belongingness needs where social affiliation is paramount. In short, basic motivations such as reproduction, preservation, achievement, and belongingness direct people's important activities and propel them through the environment. Often, a self-aspect may serve multiple needs (e.g., Danielle's professor self may serve her preservation, achievement, and belongingness motives). Thus we contend that each self-aspect is developed and refined in the service of pursuing central goals and motives.

Our view that "self-aspects are canvases that reflect important goal pursuit" not only provides a systematic account for why one's multiple selves develop, but this perspective also allows for the incredible diversity and variability of self-concepts that people reveal. That is, each individual's history, goals, needs, and motives can vary considerably, resulting in very idiosyncratic constellations of self-aspects. Some people will never have an interest in parenting, not raise children, and thus will never have a self-aspect devoted to parenting. Others may have children, yet reveal important differences in their self-aspects. For example, one woman may be a driven $\mathrm{CEO}$ who leaves the majority of childcare to her partner and thus she may not even have a well-established self identity as a parent. Another woman may be a stay-at-home mom, and thus her parent self-aspect may represent one of her primary self-identities. Although these three cases differ, the absence or presence of a parenting self-aspect reflects the relative degree to which parenting comprises one's daily activities. Thus, our approach anticipates considerable diversity in the 
ways potential roles do, and do not, become part of one's self-concept rather than assuming that all people have some fixed set of roles in life (cf., Block, 1961; Serpe, 1989).

If these context-dependent multiple selves are self canvases, what content is applied to them? We contend that each self-aspect becomes associated with selfrelevant attributes that relate to meaningful goal pursuit in that context (Figure 1 rectangles). For example, Danielle's mother self-aspect maybe be composed of the attributes nurturant, loving, female, and funny because she these qualities are central to her parenting goals. However, her athlete self-aspect may be characterized by the attributes competitive, proud, and insecure because she has recently taken up running marathons to stay in shape and to relieve stress, and she is proud of her still-developing identity as a runner. In the early stages of self-aspect development, these attributes will likely be specific exemplars (e.g., "I felt proud telling my co-workers that I am going to run my first marathon," "I was proud to complete my first run of over 10 miles"), but eventually a collection of related exemplars should give rise to more abstracted semantic self-knowledge (e.g., Kihlstrom \& Klein, 1994; Klein, Loftus, Trafton, \& Fuhrman, 1992).

Indeed, there is considerable evidence from social neuroscience research involving patients with significant memory impairments (e.g., amnesias, late-stage Alzheimer's dementia) that although one's episodic memory for events can be eviscerated by brain trauma and disease, people's perceptions of their own personalities (i.e., dispositional self-knowledge based on semantic summaries of one's own traits) remain largely intact, though permanently anchored to a time point before memory impairment began (e.g., Klein et al., 2003). Dissociations between impoverished recall of specific events in one's life but availability of relatively accurate trait knowledge for the self (but not for others) illustrates how the self-concept is best characterized by several distinct, but normally interacting, memory systems (see Klein, Cosmides, Tooby, \& Chance, 2002; Klein \& Gangi, 2010).

Of course, just because one can exhibit considerable variability between contexts does not mandate that people must be so protean. We all know people who exhibit an incredible degree of equanimity in all domains of their lives. Moreover, because people often can structure environments and social interactions to reaffirm already existing self-beliefs, self-verification can serve to reinforce stability in one's self-concept as well (Swann, 1983, 2011). Yet, the fact that someone can be a diligent colleague at work yet be a boorish partier with college friends is not surprising. Even in cultures that emphasize a true self, people have no difficulty in understanding individuals who can exhibit diversity in behavior across contexts. Further, in contexts where variability is encouraged or expected (e.g., interdependent cultures), context-modulated behavior is essential for role-appropriate conduct to promote social harmony. For instance, a man living in a southeast Asian country that emphasizes interdependence may be outspoken and directive in his home but quiet and deferential in the presence of elders.

\section{THE OPERATION OF SELF-ASPECTS}

Heretofore, we have proposed that the self is a collection of self-aspects, each of which is composed of self-relevant attributes that serve significant needs, goals, and motives. These multiple selves, which are organized and represented in long- 
term memory, become activated in the context of pursuing one's goals. For example, consider that Danielle wakes up and begins her morning by running 5 miles before dropping off her children at elementary school on the way to the university to begin a day full of teaching and research. When she first wakes up, her athlete self-aspect would be activated as she grabs her running shoes and heads out the door to exercise. Once she is back in the house and getting her children ready for school, her mother self-aspect would be activated and it will continue to guide her behavior until she drops them off at school. Next, as she drives to campus, the work context will activate her professorial self-aspect, which would actuate different and specific behaviors, thoughts, and feelings. As Danielle traverses different contexts, relevant self-aspects become activated in memory and the self-relevant attributes associated with each self-aspect will direct her actions.

It is certainly well established that environmental contexts can direct one's activities, even in the absence of any explicit awareness of how such cues trigger and orchestrate goal pursuit (e.g., Bargh \& Chartrand, 1999; Fitzsimons \& Bargh, 2004). With respect to the self, it has also been long argued that a working self-concept becomes activated and serves to direct behavior (e.g., Markus, 1977; Markus \& Wurf, 1987). We assume that domain-relevant cues activate the totality of all knowledge (both consciously available and associated with the context at a nonconscious level) related to the relevant domain. Thus, the notion that environmental cues and contexts can shift the activation of one's self-concept between athletic, parental, and professional self-aspects follows nicely from this chain of reasoning.

However, we contend that this derivation offers a number of additional insights that may be less apparent. If pursuing a meaningful goal results in a particular self-aspect being activated, then only a subset of self-relevant knowledge is important in governing one's actions, goals, and feelings and other self-knowledge could actually interfere with one's objectives. Returning to the example of Danielle driving her kids to school before arriving on campus for her work day, it may be very important that she not exhibit work-related conduct (e.g., overuse of polysyllabic words) while her children are still in the car. In other words, the appropriate expression of her behavior must rely on the activation of a specific, relevant selfaspect (and perhaps, the active inhibition of goal-conflicting self-aspects) instead of the activation of her entire self-concept.

Work by Hugenberg and Bodenhausen (2004) provides evidence for the operation of these processes. Specifically, undergraduates who were members of campus sororities participated in a study where some of them had their sorority selfaspect activated by a questionnaire asking them to reflect on their sorority identity (control participants had no such priming). Afterwards, all participants completed a lexical decision task that included words related to Greek life (e.g., keg, party) and words that related to student life (e.g., study, read). In a lexical decision task, stimuli are presented on a computer monitor and participants must judge whether each item is a word (e.g., keg, study) or a nonword (e.g., gek, tudys). The datum of interest is the speed with which people can correctly classify stimuli as words, with relatively faster responses indicating greater accessibility for the relevant concepts. In their study, participants who were primed with thinking about their sorority self-aspect were faster at judging Greek-related words and slower at judging student-related words, all in comparison to control participants. These findings suggest that the activation of a self-aspect (in this case, by the priming task) 
activated knowledge relevant to the domain and inhibited knowledge irrelevant that might serve to interfere with goal pursuit in that domain.

In another study, McConnell et al. (2009) had undergraduates describe their self-aspects and associated attributes using a self-concept description task at the beginning of the school year. Specifically, these individuals identified their important self-aspects (e.g., my student self, in my romantic relationship) and assigned personality attributes (e.g., organized, emotional, insecure) from a supplied list to describe themselves in each of these domains. Later, these participants returned to the laboratory for a three-part experiment. In the first and third parts, they completed identical lexical decision tasks, each involving the same series of attributes supplied to them during the self-concept description task they completed earlier in the year. In between these lexical decision tasks, participants wrote about one of their self-aspects for $5 \mathrm{~min}$ to activate that self-aspect in memory. When comparing speed of lexical decision judgments between the two administrations (i.e., before the self-aspect priming and afterwards), participants were only faster following the priming with lexical judgments about attributes that they had idiosyncratically associated with the self-aspect they wrote about and not for their self-aspects that they did not write about. This finding further supports the position that context (in this case, instantiated by the writing exercise) activates the relevant self-aspect, which in turn increases the accessibility of attributes only associated with it.

\section{IMPLICATIONS FOR PERSONALITY AND CHRONICITY}

One upshot of this work is that because context only activates particular and highly-relevant self-aspects, there are probably few (if any) guiding constructs that define a person across all situations and circumstances. This assertion flies in the face of many perspectives ranging from basic percepts of personality theory arguing that people possess defining traits (e.g., Allport, 1955; Kelley, 1972; Kelly, 1955) to research in social psychology concluding that chronic attributes are always activated in memory and guide one's actions regardless of context (e.g., Bargh, Bond, Lombardi, \& Tota, 1986; Markus, 1977; Markus, Smith, \& Moreland, 1985). Work on chronicity (and on self-schematicity) proposes that repeated activation of selfrelevant constructs over time increases their accessibility to the point where they are always active even in the absence of recent activation (e.g., Bargh, 1982; Bruner, 1957; Markus, 1977). Although the principles of activation, decay, and enhanced accessibility in memory are well-established (e.g., Hayes-Roth, 1977; Higgins, Bargh, \& Lombardi, 1985), if self-knowledge is organized around context-dependent self-aspects, then even the impact of chronic attributes may be more localized and context specific than previously acknowledged.

Indeed, work in our lab has shown that chronic attributes are context specific rather than context independent (Brown \& McConnell, 2009). In two different studies, participants' chronic attributes were assessed using traditional measures (e.g., asking people to list attributes common in people they like, dislike) such as those developed by Higgins, King, and Mavin (1982) and used frequently in the research literature. In addition to reporting their chronic traits, participants also completed the self-concept description task (i.e., identifying their self-aspects and listing the attributes associated with each one) described previously. By comparing these two sources of input (i.e., people's chronic traits, the trait attributes 
people used to describe each of their self-aspects), we were able to identify which self-aspects were, and were not, associated with a participant's chronic traits. Later as part of an experimental priming manipulation, the participants wrote for $5 \mathrm{~min}$ about a self-aspect that either was, or was not, associated with their chronic traits. Afterwards, they made judgments about either themselves (e.g., speeded judgments about whether traits were self-descriptive) or about others (e.g., assessing ambiguous behaviors that could potentially be interpreted as in line with their chronic traits), with self judgments and judgments of others examined in separate studies. In both studies, participants showed the chronicity effects previously reported in the literature (e.g., faster me judgments for a chronic trait than for a nonchronic trait, assimilating others' behaviors in line with their chronic traits) only when the writing exercise primed a self-aspect associated with a chronic trait but not when the writing task primed a self-aspect that was unrelated to a chronic trait. Thus, outcomes associated with chronicity were only observed when a selfaspect associated with the chronic attribute was activated, indicating that chronic traits are not always turned on, serving to influence perception and behavior in all circumstances.

Although the above study suggests that chronic attributes are more circumscribed than previously acknowledged, we would contend that the general idea that invariant qualities (e.g., personality characteristics, chronic traits) always direct one's actions is probably overstated (see also, Mischel, 1973; Mischel \& Shoda, 1995). That is not to say that important, broad-based personality attributes do not exist, but their applicability probably varies considerably across domains and social contexts. Thus, it is not unreasonable for a crafty and lucrative used car salesman to also be an honest and sincere family man or for an easygoing and patient elementary school teacher to be competitive and aggressive when she is on the soccer field. In short, the nature of self-aspects means that context only activates a subset of goal-relevant self-knowledge, and thus one's thoughts, actions, and feelings may vary considerably across situations.

\section{IMPLICATIONS FOR AFFECT}

Conceptualizing the self as collections of context-dependent self-aspects that reflect important goals, needs, and motivations also allows us to more precisely understand the link between the self and affect. From the perspective of the self being composed of multiple selves, we would anticipate that one's general affective states are directly linked to evaluations of particular self-aspects. Indeed, we have found that common measures of mood (e.g., Watson, Clark, \& Tellegen, 1988) and of self-esteem (e.g., Rosenberg, 1965) are significantly correlated to the average evaluation of the positivity of one's self-aspects (McConnell, 2011).

In other research, we further examined the relations between self-aspects and affect (McConnell et al., 2009). First, undergraduate participants' self-concepts were assessed using the self-concept description task and their initial mood was measured. Next, we provided these participants with noncontingent, experimentallymanipulated feedback that was either positive (e.g., you are in the top $10 \%$ of students in terms of having fulfilling romantic relationships) or negative (e.g., you are in the bottom $10 \%$ of students in terms of having fulfilling romantic relationships), which was purportedly based on their interpretations of ambiguous inkblot 
images (for details, McConnell et al., 2009; McConnell, Rydell, \& Leibold, 2002). Feedback was either provided about a social domain (i.e., dating self) or about an achievement domain (i.e., student self), but this domain manipulation did not qualify the results. After providing participants with the feedback, participants evaluated the positivity of each of their self-aspects (including the self-aspect related to the feedback) and provided a post-feedback measure of their mood.

Not surprisingly, participants who received positive feedback were in better moods at the end of the study than those who received negative feedback. But more important, the magnitude of their mood change was accounted for by how the feedback altered their evaluation of the self-aspect associated with the feedback. For example, participants' moods improved after being told they were in the top $10 \%$ in romantic relationships to the extent that they evaluated their dating self-aspect more positively following the feedback (e.g., their dating self-aspect evaluations fully mediated their change in mood). On the other hand, mood did not change for those whose feedback (positive or negative) did not significantly impact their evaluations of the relevant self-aspect. In other words, self-relevant feedback activated the relevant self-aspect (e.g., dating self), and its impact on overall affect was driven by how this feedback altered people's perception of their self-aspect. Thus, general affect (in this case, mood) was a by-product of how selfrelevant feedback changed one's view of a specific (and currently activated) selfaspect.

\section{INSIGHTS FOR A STABLE YET VARIABLE SELF-CONCEPT}

Our analysis not only speaks to how context leads to different facets of the self being revealed (e.g., one being playful and lovestruck at an amusement park on a date vs. one being anxious and calculating in the boardroom at work), but it also explains how the self can be both variable and stable (see also, Markus \& Kunda, 1986). Fluidity is exhibited when context activates diverse self-aspects that consume consciousness and working memory in the moment, yet consistency is maintained because each self-aspect is stored in an integrated long-term memorial representation of one's self-concept. People can have an awareness of their multifaceted selves, yet in the moment, only relevant slices of their overall self-concept are activated and alternative components are silent or competing identities are suppressed.

Thus, even when the content associated with one's self-aspects are diverse and differentiated, the activation of particular self-aspects and nonactivation or active inhibition of alternative self-aspects ensures that a singular and context-specific multiple self is expressed. If a new context calls for alternative qualities of the self to be exhibited, a different self-aspect will be activated and accessible from memory. On the other hand, not everyone necessarily possesses such divergent, differentiated self-aspects. For example, people who are lower in self-complexity report having self-aspects composed of more similar (rather than dissimilar) attributes, and these individuals tend to exhibit more consistent behaviors and evenkeeled emotions across contexts and across time (e.g., Linville, 1987; McConnell et al., 2009). 


\section{SELF-CONCEPT DEVELOPMENT AND CHANGE}

Because our perspective anticipates that the self can be variable, an important question to consider is how and when does one's self-concept change? Unfortunately, our understanding of the development and evolution of self-concepts is nascent in part because much of the existent literature examines self-concept in a snapshot fashion (e.g., studies involving undergraduates' perceptions of themselves at one point in time) or examines specific issues such as when children become self-aware (e.g., Lewis \& Ramsay, 2004). Some research has explored the development of self-esteem and domain-specific competencies (e.g., Harter, 1992; Marsh \& Ayotte, 2003), but there have been few investigations involving the development of self-concept representation (but see Amiot, de la Sablonnière, Terry, \& Smith, 2007; Marsh \& Shavelson, 1985; Shavelson, Hubner, \& Stanton, 1976). For example, much of the work during the past 30 years examining children's self-concepts involves assessing competencies in several fixed domains (e.g., peer relations, math) of interest to educators (e.g., Marsh \& Ayotte, 2003; Marsh \& Craven, 2006) rather than assessing people's idiosyncratic self-concept representations or considering the self outside of the classroom (which, based on the current analysis, is a particular context in itself).

Some of the most interesting, relevant work has involved patients who have experienced significant memory disruptions (e.g., amnesias, Alzheimer's dementia). Findings from these neuropsychological studies suggest that self-knowledge is the product of multiple, interacting systems involving general and self-specific episodic memory and semantic memory. For example, Klein and Gangi (2010) discuss the cases of several patients who have experienced significant memory disruptions. As noted previously, although episodic memory for oneself can be compromised, patients can often accurately report on their own personalities (i.e., semantic knowledge summaries about the self) up until the point where their memory was impacted. Moreover, it appears that self-relevant semantic summary memory is distinct from general social memory in that patients who can accurately report on their own personality characteristics (at least, their own premorbid qualities) reveal difficulties in describing the personalities of close others (e.g., one's own daughter). In short, it appears that semantic summary knowledge for the self such as an awareness of one's own abstract qualities is initially based upon episodic memories but is ultimately represented in a separate store that is less subject to compromise (Klein et al., 2002, 2003), which should contribute to self-concept consistency across time.

In addition to relying on neuropsychological case studies, we would also urge researchers (e.g., social psychologists, developmental psychologists) to adopt some of the tools of self-concept representation described above (e.g., self-concept description tasks, lexical decision tasks) to explore the development and revision of self-concepts in a more systematic and longitudinal fashion with individuals who have not experienced brain damage. Consistent with the neuropsychological reviewed previously, new episodic self-relevant knowledge should lead to selfconcept updating, which in turn can result in structural rewriting of one's selfconcept. But in addition to incorporating new episodic knowledge, our analysis would also anticipate that self-concept change will occur when people find themselves in novel contexts or adopt new and significant life goals. That is, if the self is 
composed of a collection of context-dependent multiple selves, it will be most subject to change when pre-existing self-aspects cannot effectively guide one's actions or when brand new goals are undertaken. Thus changes in goals, such as entering puberty or starting a family will introduce brand new objectives that will require the development of new self-aspects to pursue these new agendas effectively. And similarly, new contexts, such as going to college, experiencing marriage or divorce, or changing careers will probably produce, eliminate, or alter one's self-aspects. To summarize, our framework provides suggestions for when self-concept change is most likely to occur (e.g., adopting new life goals, finding oneself in novel contexts) and identifies methodologies that can be leveraged to explore questions related to the development, acquisition, and removal of various aspects of the self.

\section{SELF-CONCEPT ATTRIBUTES ARE MORE THAN JUST TRAITS}

So far, our description of an individual's self-concept attributes have been primarily trait based, but it is important to acknowledge that such a view is certainly too narrow. Although many approaches to self-concept representation focus on the self as being composed of personality traits (e.g., Cantor \& Kihlstrom, 1987; Klein, Sherman, \& Loftus, 1996; Linville, 1987; Roberts \& Donahue, 1994; Showers, 1992), it is certainly the case that self-knowledge transcends trait summaries. For example, Carlston's (1994) Associated Systems Theory (AST) assumes that social representation is composed not only of personality traits, but also of other types of information including affective and emotional responses, physical appearance details, embodied knowledge, social category memberships, and behavioral responses among others. With respect to self-concept representation in particular, Schleicher and McConnell (2005) modified a self-concept description task by providing participants with eight different attribute types derived from AST. Those researchers found that self-concept descriptions based on this broader array of attribute types (vs. based solely on personality traits) provided greater utility for predicting well-being outcomes ranging from depression to self-esteem.

The recognition that self-knowledge is "more than just traits" is important for a number of reasons. First, conceiving any social entity as composed of personality traits reflects a cultural bias that views social knowledge more through the lens of independent than interdependent self-construals (e.g., Markus \& Kitayama, 1991; Miller, 1984; Shweder \& Bourne, 1984). Second, considerable work on embodiment illustrates that motoric and kinesthetic representations are important (e.g., Niedenthal, Barsalou, Winkielman, Krauth-Gruber, \& Ric, 2005; Smith \& Semin, 2004; Wilson, 2002), and thus, these forms of knowledge must be included in one's self-concept alongside traits and other self-relevant information. For example, a musician's rock drummer self-aspect probably includes a variety of attributes, some trait (e.g., creative, focused) and others embodied (e.g., motoric programs for rocking one's head while playing in order to maintain rhythm). Overall, although trait-based knowledge may be important in one's self-concept and may arise more prominently from accruing a larger number of self-relevant episodes (e.g., Klein et al., 1996) and from holding general expectations of behavioral consistency for the self (e.g., McConnell et al., 2002), it is important to view the content of the self in a much broader and more comprehensive fashion than simply being a vessel filled with trait knowledge. 


\section{BROADER IMPLICATIONS: SELF AS THE KNOWN AND THE KNOWER}

The notion that context activates only a subset of domain-relevant self-knowledge may shed light on even broader issues regarding the self. Thus far in this paper, we have focused on the self as the known and not as the knower (James, 1890). When researchers ask participants to complete a self-concept description task (i.e., identify their important self-aspects and list the attributes that characterize them in these context-dependent domains), participants are explicitly describing their self-concepts. In James's formulation, this is the me or the self as the known. Yet, we know from the research discussed above that context activates only a relevant subset of this self-concept in memory while remaining self-knowledge is inactive or even is actively inhibited if its content conflicts with the goals of the currently-activated self-aspect (e.g., Hugenberg \& Bodenhausen, 2004; McConnell et al., 2009). In our view, the currently activated self-aspect contributes to what James refers to as the I or the self, as the knower.

We quite deliberately choose the language contributes to in the previous sentence not to be equivocal or wishy-washy, but because we believe that some elements of each self-aspect are not available for access and that the processes governing the activation of self-aspects are often nonconscious in response to subtle cues in the environment (e.g., Bargh \& Chartrand, 1999; Nisbett \& Wilson, 1977). As such, while one can reasonably report on much of the content of each self-aspect (especially semantic summary self-knowledge), there is undoubtedly other knowledge that also applies to each self-aspect that is more associative in nature, less governed by the rules of logic and reason, and difficult to convey through language and other symbolic means (e.g., Epstein, 1991; Sloman, 1996; Smith \& DeCoster, 2000). Even in circumstances where self-presentational concerns do not operate, some self-aspect-relevant knowledge will be activated even though it is not consciously available to that person. In particular, we would expect that associative knowledge relating to one's emotions, habits, fears, intuitions, and culturallytransmitted beliefs are probably activated in a relevant context even though a person may not have any explicit ability to report on their associations with that context. Indeed, there is both theory (e.g., Gawronski \& Bodenhausen, 2006) and empirical findings (e.g., McConnell, Dunn, Austin, \& Rawn, 2011) indicating that one's in-the-moment affective experiences are shaped both by explicitly-available knowledge and also by associative knowledge that cannot be reported in a deliberative, verbal manner.

Thus, we believe that context activates a relevant self-aspect (both information that is available to the person and other associative knowledge that is not available but still important in directing behavior), and it is the entire collection of both stores of domain-specific knowledge that serves as one's in-the-moment, conscious experience of the I, or the self as the knower. The entire concert of this activated knowledge fills one's awareness and working memory, serving to filter, shape, and direct one's perception of and attention to the social world and one's place in it. Goals are pursued, behaviors are enacted, emotions are experienced, and life is lived through this activated array of domain-relevant self-knowledge. In short, if one could fully measure the totality of one's activated self-relevant knowledge (explicit and implicit), one would have an accurate assessment of the self as the knower. Just as previous research has shown that one's in-the-moment enjoyment 
of a piece of chocolate reflects both conscious and nonconscious chocolate attitudes (McConnell et al., 2011), a more complete understanding of the self as "the knower" will require the joint employment of direct (e.g., self-concept description tasks) and indirect measures of the self (e.g., lexical decision tasks).

\section{BROADER IMPLICATIONS: GOAL PURSUIT AND SELF-REGULATION}

We began our analysis by proposing that self-aspects exist to pursue important life goals, and that they are activated by contexts that serve goal attainment. Thus, it is fitting that we conclude by reflecting on how the self serves to direct goal-relevant behaviors. Some past work has proposed that context triggers goal pursuit through a number of specific "if... then..." situation-behavioral relations stored in memory (e.g., Mendoza-Denton, Ayduk, Mischel, Shoda, \& Testa, 2001; Mischel \& Shoda, 1995). Another somewhat similar approach (e.g., Gollwitzer, 1999; Gollwitzer \& Sheeran, 2006) posits that people develop implementation intentions where individuals formulate specific behavioral responses (e.g., holing up in the library to study for an entire weekend) in response to a specific situation (e.g., failing an exam). These perspectives, however, do not speak to how one's self-concept structure plays an important role in self-regulatory activities. Although people certainly can and do develop specific situation-behavior contingencies, we believe that behavioral responses are just a subset of what one experiences when engaged in self-regulatory behavior. That is, goal pursuit also reflects a range of self-relevant phenomena, including one's aspirations and emotional experiences, and that these goal-related self identities are represented in one's self-concept.

Indeed, some of the most prominent lines of research on the self have focused on self-regulatory processes (e.g., Carver, 2003; Carver \& Scheier, 1998; Higgins, 1987, 1997; Markus \& Nurius, 1986; Ryan \& Deci, 2000). These different programs of research propose a variety of temporal selves (e.g., future selves, past selves) and goal selves (e.g., ideal selves, feared selves) that guide behaviors, and moreover, that discrepancies among them provide self-regulatory feedback that directs goal attainment. It is interesting that although each of these theoretical perspectives suggests having other selves, none of them speaks directly to the representation of these selves or their operation within the self-concept more broadly.

We contend that important goals become represented in one's self-aspects (e.g., one's parenting self, one's career self). Indeed, goal-relevant selves are identified in many literatures, including self-awareness theory (e.g., Carver, 2003), future selves (e.g., Markus \& Nurius, 1986), cybernetic theory (Carver \& Scheier, 1998), self-complexity (e.g., Niedenthal, Setterlund, \& Wherry, 1992), and self-determination theory (Ryan \& Deci, 2000). We propose that current context activates a self-aspect, which can be used for social comparison with one's current behavior and feelings. Borrowing from James's (1890) framework, the I (currently accessible thoughts, emotions, and beliefs) can be compared to the me (a goal-relevant selfaspect), and discrepancies between them help identify deficiencies that need to be addressed for successful goal attainment (see also, Hanko, Crusius, \& Mussweiler, 2010; Peetz \& Wilson, 2008). 


\section{CONCLUSION}

We propose that understanding the nature of the self requires identifying its memorial properties. In particular, we advocate that one's self-concept is a collection of context-dependent self-aspects that guide one's goal-directed behaviors in specific contexts. Because these multiple selves are represented in an interrelated memory network, our approach can explain how people can show very differentiated self identities across contexts. In addition to speaking to classic issues such as how people can exhibit stability and variability for the self, our framework suggests that the nature of core personality traits and chronic attributes is more circumscribed than previously acknowledged. Not only does context constrain what facets of the self are expressed at any given moment, one's affect too is determined by the subset of self-knowledge that is activated by a particular context. More generally, our approach speaks to a number of broader issues, such as distinctions between the self as the known and the knower, and how self-aspects serve to direct goal pursuit and self-regulatory actions. In sum, viewing the self as a collection of multiple, context-dependent self-aspects in memory that serve one's important goals sheds important light on age-old questions about the nature of the self and its function in guiding human behavior.

\section{REFERENCES}

Allport, G. W. (1955). Becoming. New Haven, CT: Yale University Press.

Amoit, C. E., de la Sablonnière, R., Terry, D. J., \& Smith, J. R. (2007). Integration of social identities in the self: Toward a cognitivedevelopmental model. Personality and Social Psychology Review, 11, 364-388.

Bargh, J. A. (1982). Attention and automaticity in the processing of self-relevant information. Journal of Personality and Social Psychology, 43, 425-436.

Bargh, J. A., Bond, R. N., Lombardi, W. J., \& Tota, M. E. (1986). The additive nature of chronic and temporary sources of construct accessibility. Journal of Personality and Social Psychology, 50, 869-878.

Bargh, J. A., \& Chartrand, T. L. (1999). The unbearable automaticity of being. American Psychologist, 54, 462-479.

Block, J. (1961). Ego-identity, role variability, and adjustment. Journal of Consulting and Clinical Psychology, 25, 392-397.

Bower, G. H., \& Gilligan, S. G. (1979). Remembering information related to one's self. Journal of Research in Personality 13, 420-432.
Brown, C. M., \& McConnell, A. R. (2009). When chronic isn't chronic: The moderating role of active self-aspects. Personality and Social Psychology Bulletin, 35, 3-15.

Brown, C. M., \& McConnell, A. R. (2011). Discrepancy-based and anticipated emotions in behavioral self-regulation. Emotion, 11, 1091-1095.

Bruner, J. S. (1957). On perceptual readiness. Psychological Review, 64, 123-152.

Cantor, N., \& Kihlstrom, J. F. (1987). Personality and social intelligence. Englewood Cliffs, NJ: Prentice-Hall.

Carlston, D. E. (1994). Associated systems theory: A systematic approach to cognitive representations of persons. In R. S. Wyer (Ed.), Advances in social cognition (Vol. 7, pp. 1-78). Hillsdale, NJ: Erlbaum.

Carver, C. S. (2003). Self-awareness. In M. R. Leary \& J. P. Tangney (Eds.), Handbook of self and identity (pp. 179-196). New York: Guilford.

Carver, C. S., \& Scheier, M. F. (1998). Attention and self-regulation: A control-theory approach to human behavior. New York: Springer-Verlag. 
Epstein, S. (1991). Cognitive-experiential Selftheory: An integrative theory of personality. In R. Curtis (Ed.), The relational self: Convergences in psychoanalysis and social psychology (pp. 111-137). New York: Guilford.

Fitzsimons, G. M., \& Bargh, J. A. (2004). Automatic self-regulation. In R. F. Baumeister \& K. D. Vohs (Eds.), Handbook of self-regulation (pp. 151-170). New York: Guilford.

Gawronski, B., \& Bodenhausen, G. V. (2006). Associative and propositional processes in evaluation: An integrative review of implicit and explicit attitude change. Psychological Bulletin, 132, 692-731.

Gollwitzer, P. M. (1999). Implementation intentions: Strong effects of simple plans. American Psychologist, 54, 493-503.

Gollwitzer, P. M., \& Sheeran, P. (2006). Implementation intentions and goal achievement: A meta-analysis of effects and processes. Advances in Experimental Social Psychology, 38, 69-119.

Greenwald, A. G., \& Banaji, M., R. (1989). The self as a memory system: Powerful, but ordinary. Journal of Personality and Social Psychology, 57, 41-54.

Hanko, K., Crusius, J., \& Mussweiler, T. (2010). When I and me are different: Assimilation and contrast in temporal self-comparisons. European Journal of Social Psychology, 40, 160-168.

Harter, S. (1992). The relationship between perceived competence, affect, and motivational orientation within the classroom: Processes and patterns of change. In A. K. Boggiano \& T. S. Pittman (Eds.), Achievement and motivation: A social-developmental perspective (pp. 77-113). New York: Cambridge University Press.

Hayes-Roth, B. (1977). Evolution of cognitive structures and processes. Psychological Review, 84, 260-278.

Higgins, E. T. (1987). Self-discrepancy: A theory relating self and affect. Psychological Review, 94, 319-340.

Higgins, E. T. (1997). Beyond pleasure and pain. American Psychologist, 52, 1280-1300.

Higgins, E. T., Bargh, J. A., \& Lombardi, W. (1985). The nature of priming effects on categorization. Journal of Experimental Psychology: Learning, Memory and Cognition, 11, 59-69.
Higgins, E. T., King, G. A., \& Mavin, G. H. (1982). Individual construct accessibility and subjective impressions and recall. Journal of Personality and Social Psycholo$g y, 43,35-47$.

Hugenberg, K., \& Bodenhausen, G. V. (2004). Category membership moderates the inhibition of social identities. Journal of Experimental Social Psychology, 40, 233-238.

James, W. (1890). The principles of psychology. New York: Henry Holt.

Kelley, H. H. (1972). Attribution in social interaction, In E. E. Jones, D. E. Kanouse, H. H. Kelley, R. E. Nisbett, S. Valins, \& B. Weiner (Eds.), Attribution: Perceiving the causes of behavior (pp. 1-26). Morristown, NJ: General Learning Press.

Kelly, G. A. (1955). The psychology of personal constructs (Vols. 1 \& 2). New York: Norton.

Kihlstrom, J. F., \& Klein, S. B. (1994). The self as a knowledge structure. In R. S. Wyer \& T. K. Srull (Eds.), Handbook of social cognition (2nd ed., Vol. 1, pp. 153-208). Hillsdale, NJ: Erlbaum.

Klein, S. B., Cosmides, L., \& Costabile, K. (2003). Preserved knowledge of self in a case of Alzheimer's dementia. Social Cognition, 21, 157-165.

Klein, S. B., Cosmides, L., Tooby, J., \& Chance, S. (2002). Decisions and the evolution of memory: Multiple systems, multiple functions. Psychological Review, 109, 306-329.

Klein, S. B., \& Gangi, C. E. (2010). The multiplicity of self: Neuropsychological evidence and its implications for the self as a construct in psychological research. Annals of the New York Academy of Sciences, 1191, 1-15.

Klein, S. B., \& Kihlstrom, J. F. (1986). Elaboration, organization, and the self-reference effect in memory. Journal of Experimental Psychology: General, 115, 26-38.

Klein, S. B., Loftus, J., Trafton, J. G., \& Fuhrman, R. W. (1992). Use of exemplars and abstractions in trait judgments: A model of trait knowledge about the self and others. Journal of Personality and Social Psychology, 63, 739-753.

Klein, S. B., Sherman, J. W., \& Loftus, J. (1996). The role of episodic and semantic memory in the development of trait 
self-knowledge. Social Cognition, 14, 277-291.

Kurzban, R., \& Aktipis, C. A. (2007). Modularity and the social mind: Are psychologists too self-ish? Personality and Social Psychology Review, 11, 131-149.

Lewis, M., \& Ramsay, D. (2004). Development of self-recognition, personal pronoun use, and pretend play during the 2nd year. Child Development, 75, 1821-1831.

Linville, P. W. (1987). Self-complexity as a cognitive buffer against stress-related illness and depression. Journal of Personality and Social Psychology, 52, 663-676.

Linville, P. W., \& Carlston, D. E. (1994). Social cognition perspective on self. In P. G. Devine, D. L. Hamilton, \& T. M. Ostrom (Eds.), Social cognition: Contributions to classic issues in social psychology (pp. 143193). New York: Springer-Verlag.

Markus, H. R. (1977). Self-schemata and processing information about the self. Journal of Personality and Social Psychology, $35,63-78$.

Markus, H. R., \& Kitayama, S. (1991). Culture and the self: Implications for cognition, emotion, and motivation. Psychological Review, 98, 224-253.

Markus, H. R., \& Kunda, Z. (1986). Stability and malleability of the self-concept. Journal of Personality and Social Psycholo$g y, 51,858-866$.

Markus, H. R., \& Nurius, P. (1986). Possible selves. American Psychologist, 41, 954-969.

Markus, H., Smith, J., \& Moreland, R. L. (1985). Role of the self-concept in the perception of others. Journal of Personality and Social Psychology, 49, 1494-1512.

Markus, H. R., \& Wurf, E. (1987). The dynamic self-concept: A social psychological perspective. Annual Review of Psychology, 38, 299-337.

Marsh, H. W., \& Ayotte, V. (2003). Do multiple dimensions of self-concept become more differentiated with age? The differential distinctiveness hypothesis. Journal of Educational Psychology, 95, 687-706.

Marsh, H. W., \& Craven, R. G. (2006). Reciprocal effects of self-concept and performance from a multidimensional perspective: Beyond seductive pleasure and unidimensional perspectives. Perspectives on Psychological Science, 1, 133-163.
Marsh, H. W., \& Shavelson, R. (1985). Selfconcept: Its multifaceted, hierarchical structure. Educational Psychologist, 20, 107-123.

McConnell, A. R. (2011). The multiple self-aspects framework: Self-concept representation and its implications. Personality and Social Psychology Review, 15, 3-27.

McConnell, A. R., Dunn, E. W., Austin, S. N., \& Rawn, C. D. (2011). Blind spots in the search for happiness: Implicit attitudes and nonverbal leakage predict affective forecasting errors. Journal of Experimental Social Psychology, 47, 628-634.

McConnell, A. R., Renaud, J. M., Dean, K. K., Green, S. P., Lamoreaux, M. J., Hall, C. E., \& Rydell, R. J. (2005). Whose self is it anyway? Self-aspect control moderates the relationship between self-complexity and well-being. Journal of Experimental Social Psychology, 41, 1-18.

McConnell, A. R., Rydell, R. J., \& Brown, C. M. (2009). On the experience of self-relevant feedback: How self-concept organization influences affective responses and self-evaluations. Journal of Experimental Social Psychology, 45, 695-707.

McConnell, A. R., Rydell, R. J., \& Leibold, J. M. (2002). Expectations of consistency about the self: Consequences for selfconcept formation. Journal of Experimental Social Psychology, 38, 569-585.

McConnell, A. R., \& Strain, L. M. (2007). Content and structure of the self. In C. Sedikides \& S. Spencer (Eds.), The self in social psychology (pp. 51-72). New York: Psychology Press.

Mendoza-Denton, R., Ayduk, O., Mischel, W., Shoda, Y., \& Testa, A. (2001). Person x Situation interactionism in self-encoding (I am... when...): Implications for affect regulation and social information processing. Journal of Personality and Social Psychology, 80, 533-544.

Miller, J. G. (1984). Culture and the development of everyday social explanation. Journal of Personality and Social Psycholo$g y, 46,961-978$.

Mischel, W. (1973). Toward a cognitive social learning reconceptualization of personality. Psychological Review, 80, 252-283.

Mischel, W., \& Shoda, Y. (1995). A cognitiveaffective system theory of personality: Reconceptualizing situations, dispositions, dynamics, and invariance in per- 
sonality structure. Psychological Review, 102, 246-268.

Niedenthal, P. M., Barsalou, L. W., Winkielman, P., Krauth-Gruber, S., \& Ric, F. (2005). Embodiment in attitudes, social perception, and emotion. Personality and Social Psychology Review, 9, 184-211.

Niedenthal, P. M., Setterlund, M. B., \& Wherry, M. B. (1992). Possible self-complexity and affective reactions to goal-relevant evaluation. Journal of Personality and Social Psychology, 63, 5-16.

Nisbett, R. E., \& Wilson, T. D. (1977). Telling more than we can know: Verbal reports on mental processes. Psychological Review, 84, 231-259.

Peetz, J., \& Wilson, A. E. (2008). The temporally extended self: The relation of past and future selves to current identity, motivation, and goal pursuit. Social and Personality Psychology Compass, 2, 2090-2106.

Renaud, J. M., \& McConnell, A. R. (2002). Organization of the self-concept and the suppression of self-relevant thoughts. Journal of Experimental Social Psychology, $38,79-86$.

Roberts, B. W., \& Donahue, E. M. (1994). One personality, multiple selves: Integrating personality and social roles. Journal of Personality, 62, 199-218

Rosenberg, M. (1965). Society and the adolescent self-image. Princeton, NJ: Princeton University Press.

Ryan, R. M., \& Deci, E. L. (2000). Self-determination theory and the facilitation of intrinsic motivation, social development, and well-being. American Psychologist, $55,68-78$.

Schleicher, D. J., \& McConnell, A. R. (2005). The complexity of self-complexity: An associated systems theory approach. Social Cognition, 23, 387-416.

Serpe, R. T. (1989). Stability and change in self: A structural symbolic interactionist explanation. Social Psychological Quarterly, 50, 44-55.

Shavelson, R. J., Hubner, J. J., \& Stanton, G. C. (1976). Validation of construct interpretations. Review of Educational Psychology, 46, 407-441.

Showers, C. (1992). Compartmentalization of positive and negative self-knowledge: Keeping bad apples out of the bunch. Journal of Personality and Social Psycholo$g y, 62,1036-1049$.
Showers, C. J., \& Zeigler-Hill, V. (2003). Organization of self-knowledge: Features, functions, and flexibility. In M. R. Leary \& J. P. Tangney (Eds.), Handbook of self and identity (pp. 47-67). New York: Guilford Press.

Shweder, R. A., \& Bourne, E. J. (1984). Does the concept of the person vary cross-culturally? In R. A. Shweder \& R. A. LeVine (Eds.), Culture theory: Essays on mind, self, and emotion (pp. 158-199). New York: Cambridge University Press.

Sloman, S. A. (1996). The empirical case for two systems of reasoning. Psychological Bulletin, 119, 3-22.

Smith, E. R., \& DeCoster, J. (2000). Dual-process models in social and cognitive psychology: Conceptual integration and links to underlying memory systems. Personality and Social Psychology Review, 4, 108-131.

Smith, E. R., \& Semin, G. R. (2004). Socially situated cognition: Cognition in its social context. Advances in Experimental Social Psychology, 36, 53-117.

Spencer-Rodgers, J., Williams, M. J., \& Peng, K. (2010). Cultural differences in expectations of change and tolerance for contradictions: A decade of empirical research. Personality and Social Psychology Review, 14, 296-312.

Swann, W. B. (1983). Self-verification: Bringing social reality into harmony with the self. In J. Suls \& A. G. Greenwald (Eds.), Social psychological perspectives on the self (Vol. 2, pp. 33-66). Hillsdale, NJ: Erlbaum.

Swann, W. B. (2011). Self-verification theory. In P. van Lang, A. Kruglanski, \& E. T. Higgins (Eds.), Handbook of theories of social psychology (pp. 23-42). London: Sage Press.

Triandis, H. C. (1989). The self and social behavior in differing cultural contexts. Psychological Review, 96, 506-520.

Watson, D., Clark, L. A., \& Tellegen, A. (1988). Development and validation of brief measures of positive and negative affect: The PANAS scales. Journal of Personality and Social Psychology, 54, 1063-1070.

Wilson, M. (2002). Six views of embodied cognition. Psychonomic Bulletin and Review, 9, 625-636. 